in already well described genera. Based on the criteria of biochemical tests, electronmicroscopy, and DNA homology, the 22 strains could not be placed in an existing genus. Therefore, a new genus Mobiluncus (mobilis capable of movement, uncus a hook, Mobiluncus a mobile curved rod) was proposed. This has a guanine: cystosine ratio of $49-52 \%$.

To our knowledge this is the first isolation outside the genital tract of Mobiluncus sp in this country. There is one report of a confirmed isolation outside the genital tract from the Netherlands, ${ }^{3}$ and a series of four patients from Belgium ${ }^{4}$ where it was deduced retrospectively that the isolates belonged to the Mobiluncus genus.

Anaerobic breast abscess due to Bacteroides species, often in association with other anaerobes, has been well documented. ${ }^{56}$ Leach $e t a l^{5}$ concluded that anaerobic breast abscesses occur in non-puerperal women with inverted nipples and postulated that the source of the organism was either the vagina or the oropharynx rather than the bowel. In the only confirmed report of Mobiluncus isolated from a breast abscess the patient was not pregnant and had inverted nipples. ${ }^{3}$ Our patient was also not pregnant and had a prosthetic breast implant following surgery for duct ectasia. The implant would have provided a focus for organisms to settle, similar to the focus offered by duct ectasia or chronic breast disease in patients with inverted nipples, the organism gaining access to the breast either by bacteraemia or by direct transfer from the genital tract. There was no history of vaginal "discharge" at presentation, nor was it specifically looked for, consequently no high vaginal swab was taken at the time.

It seems likely, therefore, that the same mechanism may operate for both Bacteroides and Mobiluncus spp in causing breast abscess, although at present, there have been too few isolates of Mobiluncus spp to be certain.

MJ WEINBREN RM PERINPANAYAGAM H MALNICK* F ORMEROD

Department of Microbiology, Queen Mary's Hospital, Roehampton Lane, London SW15 5PN

*NCTC, Central Public Health Laboratory, 61 Colindale Avenue, London NW9 5 H6

References

${ }^{1}$ Bacterial vaginosis. Pardh P-A, Taylor-Robinson D, eds. Stockholm: Amlqvist and Wiksell International, 1984.
${ }^{2}$ Spiegel CA, Roberts M. Mobiluncus gen nov, Mobiluncus curtisii subsp curtisii sp now, Mobiluncus curtisii subsp holmesii subsp now, and Mobiluncus mulieris sp nov, Curved rods from the human vagina. International Journal of Systematic Bacteriology 1984;34: 177-84.

${ }^{3}$ Sturm AW, Sikkenk PJH. Anaerobic curved rods in breast abscess. Lancet 1984;ii: 1216.

${ }^{4}$ Glupczynski Y, Labbe M, Crokaert F, et al. Isolation of Mobiluncus in four cases of extragenital infections in adult women. Eur J Clin Microbiol 1984;3:433-5.

${ }^{5}$ Leach RD, Eykyn AJ, Phillips I, Corrin B. Anaerobic subareolar breast abscess. Lancet 1979;i:35-7.

${ }^{6}$ Hale JE, Perinpanayagam RM, Smith G. Bacteroides: an unusual cause of breast abscess. Lancet 1976;ii:70.

Detection and importance of $\beta$ lactamase producing "non-pathogens" in patients with chronic obstructive airways disease

Since $\beta$ lactamase activity was first described in 1940 by Abraham and Chain ${ }^{1}$ attention has been directed to its detection and clinical importance in body secretions. In 1945 Gots $^{2}$ described a rapid method for determining whether organisms produce penicillinase, using a penicillin agar medium inoculated with an organism sensitive to penicillin.

In recent years it has been reported that $\beta$ lactamase producing "non-pathogenic bacteria" have contributed to the failure of $\beta$ lactamase treatment in patients with respiratory infections. ${ }^{34}$ The commonest $\beta$ lactamase producing organisms described are Staphylococcus aureus, Haemophilus influenzae, Haemophilus parainfluenzae, Branhamella catarrhalis and Bacteroides spp. $^{3}$

This report sets out to show whether such production of $\beta$ lactamase is clinically important in patients with acute exacerbations of chronic obstructive airways disease (COAD), who are often treated with ampicillin.

Between September 1984 and March 1985 a random selection of sputum from patients with exacerbations of COAD was made. The specimens were cultured for respiratory pathogens and subsequently were examined for $\beta$ lactamase produced from "nonpathogens" present in the upper or lower respiratory tract.

A modified Gots's ${ }^{2}$ technique was used using mannitol salt agar containing 1.6 $\mu \mathrm{g} / \mathrm{ml}$ of penicillin - that is, four times the minimal inhibitory concentration of penicillin to Staphylococcus aureus NCTC 6571. This was seeded with a four hour broth culture of $S$ aureus NCTC 6571. Size 4 wells were punched out and half filled with sputolysed sputum (Stat-Pack Dithiothreitol solution, Calbiochem-Behring). The following morning they were examined for growth of $S$ aureus on the surface of the agar. In those which showed growth the sputum cultures were re-examined, each isolate being tested for production of $\beta$ lactamase, using Mast intralactam strips. Of the 105 sputa tested, only six showed evidence of $\beta$ lactamase activity. There were no Haemophilus influenzae producing $\beta$ lactamase in the group, and examination of the culture of the sputa showed no organisms producing $\beta$ lactamase.

Of the six positive sputa showing $\beta$ lactamase activity, culture yielded upper respiratory tract flora in three cases and Streptococcus pnuemoniae in three cases, two of which responded to amoxycillin, the third patient died of carcinomatosis of the lung the day the specimen was taken.

The increased incidence of production of $\beta$ lactamase by Haemophilus $s p p^{5}$ has created a dilemma in the choice of initial antibiotic treatment in patients with exacerbations of COAD. In an area with a relatively low prevalence of $\beta$ lactamase producing Haemophilus influenzae (less than $1 \%$ in this hospital) it seems that ampicillin is appropriate first line treatment in these patients, in view of the low incidence of $\beta$ lactamase in their sputum.

EG SMYTH
F AHMAD
AC SHAW
Public Health Laboratory,
Central Middlesex Hospital,
Acton Lane,
London NW10 $7 N S$

References

${ }^{1}$ Abraham EP, Chain E. An enzyme from bacteria able to destroy penicillin. Nature 1940; 146:837.

${ }^{2}$ Gots J. The detection of penicillinase-producing properties of micro-organisms. Science 1945; 102:309.

${ }^{3}$ Brook I, Gober A. Rapid method for detecting $\beta$ lactamase producing bacteria in clinical specimens. J Clin Pathol 1984;37:1392-4.

${ }^{4}$ Maddocks JL. Indirect pathogenicity. J Antimicrob Chemother 1980;6:307-9.

${ }^{5}$ Philpott AJ, Philpott-Howard J, Williams JD. Increase in antibiotic resistance in haemophilus influenzae in the UK since 1977. $\mathrm{Br}$ Med J 1983;284:1597-9.

\section{Biphenotypic leukaemia}

We previously reported a case of biphenotypic leukaemia (T acute lymphoblastic leukaemia and acute mycloblastic leukaemia) 